\title{
Malignancy Prediction of Gastrointestinal Stromal Tumors by Evaluating Tumor Vessel Density from Enhanced Spiral CT Scan
}

\author{
Jintao Li, Cihu Yu, Chang Li, Yanzhuo Su and Libo Sun* \\ Department of Gastrointestinal Colorectal and Anal Surgery, China-Japan Union Hospital of Jilin University, Changchun, China \\ ${ }^{*}$ Corresponding author
}

\begin{abstract}
Purpose The aim of this study was to evaluate the role of tumor blood vessel density from enhanced spiral CT Scan in the malignancy prediction of small bowel gastrointestinal gist tumors (GISTs). Methods Altogether twenty five cases of small bowel GISTs were included. The malignancy grade was classified as benign small bowel stromal tumors (BSS), uncertain malignant potential small bowel stromal tumors (UMPSS), and malignant small bowel stromal tumors (MSS). All the patients received enhanced abdominal CT, and three dimensional imaging of tumor blood vessels were constructed based on the enhanced CT examination, which were input and measured by a software system measure the tumor vessel density (TVD). Results Significant TVD difference was found among the three group $(P=0.000)$, and significant difference was also found between BMS and UPMSS, BMS and MSS, UPNSS and MSS group.(P= $0.016, P=0.011$, and $P=0.038$ respectively). TVD level in $\mathrm{Ki}-67$ positive group is significantly higher than that of $\mathrm{Ki}-67$ negative group $(P=0.011)$. Conclusion This study suggested that preoperative measurement of TVD from enhanced three dimensional CT scan can help predict the malignancy extent of small bowel GISTs.
\end{abstract}

Keywords-gastrointestinal stromal tumors; tumor vessel density; CT Scan

\section{INTRODUCTION}

Gastrointestinal stromal tumors (GISTs) are the most common mesenchymal tumors of the gastrointestinal (GI) tract, and the morbidity has the tendency to increase ${ }^{[1,2]}$. Small bowel GISTs account for $20 \%$ to $45 \%$ of GISTs, but they showed more aggressive biobehaviors and poor prognosis ${ }^{[3-5]}$. The symptoms of small bowel GISTs are usually not typical in the early stage, and after growing up, tumors may presented as abdominal mass, intestinal obstruction, and GI bleeding before they were confirmed by surgery and pathology examinations [2-5]. The malignancy level of small bowel GISTs is usually identified by postoperative pathological and immunobiochemical examination according to the tumor size, mitosis rate, and the expression level of Ki-67, one of the most frequent biomarkers investigated on GISTs ${ }^{[6,}{ }^{7]}$.Surgical resection is the first choice for those removable small bowel GIST, and for primary unresectable, metastatic and recurrent GISTs, targeted chemotherapy agent inatinib was recommended ${ }^{[8,9]}$.
Angiogenesis, formation of new blood vessels, is the critical factor for tumor growth and metastasis, and plays an important role in the development of GISTs [10,11]. A common method to detect the tumor vessel level is to measure the microvessel density (MVD) in the tissue sample, which is considered as an index of survival for patients with GISTs [12, 13]. The aim of this study was to evaluate the role of tumor blood vessel density from enhanced spiral CT Scan in the malignancy prediction of small bowel GISTs.

\section{MATERIALS AND Methods}

\section{A. Patients}

From September 2015 to September 2017, twenty five cases of small bowel GISTs, that received surgery in China Japan Union Hospital were reviewed. The diagnosis of GIST was based on histopathology after surgical resection. Of the 25 patients, 14 are male and 11 are female. Age is from 18 to 70 years old with a mean age of $46.40 \pm 14.0$. The common symptoms are intestinal obstruction in eight and bleeding in seven, in whom four are bloody stool, two are intermittent melena, and one is hematemesis. Three patients need blood transfusion, with 8, 4 and 2 unit blood red cells respectively. The review of the medical records was carried out with approval by the ethics committee of our hospital.

\section{B. Surgery and Pathological Examinations}

All the 25 patients received surgical treatment. Fifteen were first explored by laparoscopy, then incision was chosen $\mathrm{d}$ near the tumor area, and tumor was removed with open approach. The other ten was treated directly by open surgery. Eighteen located at the jejunum, and seven belong to ileum. All the tumors were successfully removed and intestine to intestine anastomosis was performed. All the removed sample were checked with immunohistochemistry examinations including CD117, Dog-1, CD34, SMA, Desmin, S-100, Ki 67, SDHB, and EMA. Figure 1 showed an CD34 positive small bowel GIST. The diagnosis of GIST based on the WHO GIST classification $\left.{ }^{[14}\right]$. The malignancy grade was classified as benign small bowel stromal tumors (BSS), uncertain malignant potential small bowel stromal tumors (UMPSS), and malignantmall bowel stromal tumors (MSS), according to the tumor location, size, and mitotic figure.The template is used to 
format your paper and style the tePrepare Your Paper Before Styling.

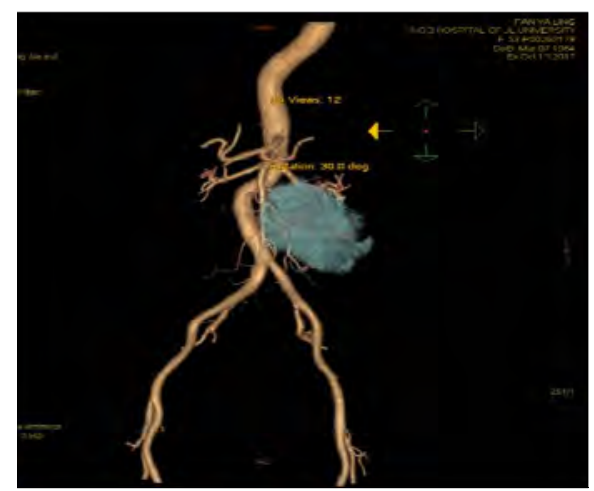

FIGURE I. THE RECONSTRUCTED THREE DIMENSIONAL IMAGE OF ONE PATIENTS FOR SMALL BOWEL GISTS

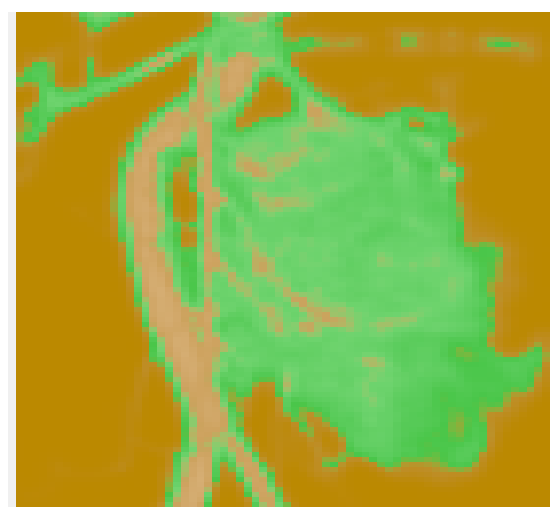

FIGURE II. THE TUMOR VESSEL DENSITY VALUED AT CERTAIN AREAS FROM RECONSTRUCTED CT IMAGE.

\section{Tumor Vessel Image Reconstruction Based on Enhanced CT}

Before operation all the patients received enhanced abdominal CT, and three dimensional imaging of tumor blood vessels were constructed based on the enhanced CT examination. Figure 1 showed the reconstructed three dimensional image of one patients for small bowel GISTs.

\section{RESULTS}

\section{A. Vessel Density Data in Different Malignant Level Group}

Significant TVD difference was found among the three group $(\mathrm{P}=0.000)$, and significant difference was also found between BMS and UPMSS, BMS and MSS, UPNSS and MSS group. $(\mathrm{P}=0.016, \mathrm{P}=0.011$, and $\mathrm{P}=0.038$ respectively) . The TVD value is listed in table 1 .

\begin{tabular}{ccccc}
\multicolumn{5}{c}{ TABLE I. TUMOR VESSEL DENSITY DATA MEASURED FROM } \\
\multicolumn{4}{c}{ ENHANCED CT SCAN AMONG DIFFERENT GROUPS } \\
\hline $\begin{array}{c}\text { KI-67 } \\
\text { expression }\end{array}$ & $\mathrm{n}$ & TVD value & $t$ value & $P$ value \\
& & & & \\
\hline+ & 17 & $0.054 \pm 0.025$ & & \\
- & 8 & $0.028 \pm 0.012$ & 2.751 & 0.011
\end{tabular}

Note: TVD: tumor vessel density; BSS: Benign Small bowel Stromal tumors; UMPSS: Uncertain Malignant Potential Small bowel stromal tumors; MSS: Malignant Small bowel stromal tumors. BMS vs UPMSS, $P=0.016$; BMS vs MSS, $P=0.011$; UPNSS vs MSS, $\mathrm{P}=0.038$.

\section{B. TVD Comparison Between Ki - 67 Expression Positive and Negative Group}

Of the 25 cases of small bowel GISTs, postoperative pathologicimmunohistochemical Ki - 67 examination showed positive in 17 cases, and negative in 8 cases. TVD level in Ki 67 positive group is significantly higher than that of $\mathrm{Ki}-67$ negative group $(P=0.011)$. The data of TVD in Ki - 67 positive and negative group was shown in table 2 .

TABLE II. TUMOR VESSEL DENSITY DATA MEASURED FROM ENHANCED CT SCAN BETWEEN POSITIVE AND NEGATIVE KI-67 EXPRESSION

\begin{tabular}{cccccc}
\hline & $\begin{array}{c}\text { BMS } \\
\text { group }\end{array}$ & $\begin{array}{c}\text { UPMSS } \\
\text { group }\end{array}$ & $\begin{array}{c}\text { MSS } \\
\text { group }\end{array}$ & $\begin{array}{c}\text { F } \\
\text { value }\end{array}$ & P value \\
\hline TVD & 0.028 & $0.039 \pm 0$. & $0.073 \pm$ & & \\
value & \pm 0.01 & 013 & 0.022 & & \\
& 1 & & & & \\
\hline
\end{tabular}

Note: TVD: tumor vessel density;

\section{Discussion}

For small bowel GISTs, early clinical manifestations are not typical, and when tumor grow up, digestive bleeding and intestinal obstruction are the common symptoms $[15,16]$. Preoperative diagnosis is mainly based on computer tomography findings and final confirmation depends on pathological and immunohistochemistry examinations [17]. Malignancy level is based on tumor size and mitosis rate $\left.{ }^{[14}\right]$. Recently tumor vessel density in the postoperative sample is considered as an indicator of malignant extent of small bowel GISTs. However this examination is performed only after operation.

In this study, we compared the TVD presented on enhanced CT three dimensional image, and found the measured TVD level is significantly correlated with malignancy extent of small bowel GISTs. Our results suggested that preoperative TVD level measured from enhanced CT can be taken as an indicator of malignancy level for small bowel GISTs. The most important of our method is that we predict the malignancy level of small bowel GISTs preoperatively, other than postoperatively. Our study also 
indicate that blood supply is the basis of growth for small bowel GIST, which is similar with other malignant tumors ${ }^{[18]}$.

Ki-67, a nuclear protein commonly expressed among proliferating cells especially in stages G1, S and G2. Therefore is considered as an objective predictor of malignant potential of GISTs ${ }^{[19,20}$. We compared the TVD level between Ki-67 expression positive and negative group, with a result of significant difference, which further suggested that the TVD level measured from enhanced spiral CT image is correlated with malignancy extent of small bowel GISTs. Because the limited cases, we could not find the correlation of Ki-67 expression extent and the TVD level measured.

In conclusion this study suggested that preoperative measurement of TVD from enhanced three dimensional CT scan can help predict the malignancy extent of small bowel GISTs.

\section{ACKNOWLEDGMENT}

We would like to thank doctor Zhang Mengchao of Radiology Department for his support in obtaining the CT scan images of the patients included, and technician Bo Lihua of Research Center of our hospital for her help in the image analysis.

\section{REFERENCES}

[1] Ma GL, Murphy JD, Martinez ME, Sicklick JK,” Epidemiology of gastrointestinal stromal tumors in the era of histology codes: results of a population-based study," Cancer Epidemiol Biomarkers Prev, vol.24, Jan 2015, pp.:298-302. doi: 10.1158/1055-9965.EPI-14-1002. Epub 2014 Oct 2.

[2] Tran T, Davila JA, El-Serag HB," The epidemiology of malignant gastrointestinal stromal tumors: an analysis of 1,458 cases from 1992 to 2000,"The American journal of gastroenterology,vol.100,Jan 2005pp.162-168.

[3] Sandvik OM, Søreide K, Gudlaugsson E, Søreide JA,” Surgery for gastrointestinal stromal tumors (GISTs) of the stomach and small bowel: short- and long-term outcomes over three decades,"World J Surg. vol.39,Feb 2015,pp.446-52. doi: 10.1007/s00268-014-2824-4.

[4] Miettinen M, Lasota J,’Gastrointestinal stromal tumors: pathology and prognosis at different sites," Semin Diagn Pathol, vol.23,May 2006,pp.70-83.

[5] .Grover S, Ashley SW, Raut CP. Small intestine gastrointestinal stromal tumors. Curr Opin Gastroenterol.2012;28:113-123.

[6] Miki Y, Kawamura T, Sugisawa N, Makuuchi R, Nakajima T, Tokunaga $\mathrm{M}$, et al, "Classification using the Ki-67 Labeling Index for SurgicallyTreated Gastric Gastrointestinal Stromal Tumors," Hepatogastroenterology, vol.62,Jun. 2015 pp.919-23.

[7] Wang H, Chen P, Liu XX, Zhao W, Shi L, Gu XW, et al,” Prognostic impact of gastrointestinal bleeding and expression of PTEN and Ki-67 on primary gastrointestinal stromal tumors," World J Surg Oncol. vol.9, Apr. 2014 , pp.12-89. doi: 10.1186/1477-7819-12-89.

[8] Shen C, Chen H, Yin Y, Chen J, Zhang B, Chen Z, et al, “. Preoperative imatinib for patients with primary unresectable or metastatic/recurrent gastrointestinal stromal tumor,” Clinics (Sao Paulo), vol.69, Nov 2014,pp.758-62. doi: 10.6061/clinics/2014(11)09.

[9] Sicklick JK, Lopez NE,” Optimizing surgical and imatinib therapy for the treatment of gastrointestinal stromal tumors," J Gastrointest Surg. vol17,Nov. 2013 ,pp.1997-2006. doi: 10.1007/s11605-013-2243-0. Epub 2013 Jun 18.

[10] Zerbini G, Lorenzi M, Palini A,” Tumor angiogenesis,” N Engl J Med. vol. 359, July 2008;pp.763. doi: 10.1056/NEJMc081278
[11] Imamura M, Yamamoto H, Nakamura N, Oda Y, Yao T, Kakeji Y,et al,”. Prognostic significance of angiogenesis in gastrointestinal stromal tumor,” Mod Pathol. vol.20, May 2007, pp. 529-537.

[12] Waengertner LE, Meurer L , Cerski MR,” Microvessel Density (Chalkley Method) in a Series of 79 Gastrointestinal Stromal Tumors," Gastroenterology Res,vol. 4, Dec. 2011, pp. 252-256.

[13] Basilio-de-Oliveira RP, Pannain VL,” Prognostic angiogenic markers (endoglin, VEGF, CD31) and tumor cell proliferation (Ki67) forgastrointestinal stromal tumors,” World J Gastroenterol, vol. 14, Jun 2015,pp. 6924-6930. doi: 10.3748/wjg.v21.i22.6924.

[14] Bosman FT , Carneiro F,Hruban RH, Theise N. WHO classifications of tumors of the digestive system. 4th ed. Lyon: IARC Press,2010, pp.7276.

[15] Chen YT,Sun HL,Luo JH,Ni JY,Chen D,Jiang XY,et al, “Interventional digital subtraction angiography for small bowel gastrointestinal stromal tumors with bleeding,” World J Gastroenterol,vol. 20, Dec.2014, pp. 17955-17961. doi: 10.3748/wjg.v20.i47.17955.

[16] Aghdassi A, Christoph A, Dombrowski F, Döring P, Barth C, Christoph J, et al, “ Gastrointestinal Stromal Tumors: Clinical Symptoms, Location, Metastasis Formation, and Associated Malignancies in a Single Center Retrospective Study,” Dig Dis, vol. 5, Jun 2018, pp. 1-9. doi: 10.1159/000489556.

[17] Su Q, Wang Q, Zhang H, Yu D, Wang Y, Liu Z, et al, "Computed tomography findings of small bowel gastrointestinal stromal tumors with different histologic risks of progression,” Abdom Radiol (NY), Feb 2018 doi: 10.1007/s00261-018-1511-6. [Epub ahead of print]

[18] Jing Y, Sun LB, Shu ZB, Li YC, Ding DY, Zhang HM, et al, "Predictive value of tumor vessel density from enhanced spiral CT scan for lymph node and distant metastasis of colorectal cancer,” Zhonghua Wei Chang Wai Ke Za Zhi, vol. 16, May 2013, pp. 448-50.

[19] Pyo JS, Kang G, Sohn JH, “Ki-67 labeling index can be used as a prognostic marker in gastrointestinal stromal tumor: a systematic review and meta-analysis,” Int J Biol Markers, Vol. 28, May. 2016, pp' e204210, doi: 10.5301/jbm.5000183.

[20] Nagasako Y, Misawa K, Kohashi S, Hasegawa K, Okawa Y, Sano H, et al.”Evaluation of malignancy using Ki-67 labeling index for gastric stromal tumor,” Gastric Cancer, vol. 6,Mar. 2003, pp.168-172, doi: 